\title{
Opioid Abuse in Interventional Pain Management
}

\section{To the Editor:}

I read with interest the article by Manchikanti et al (1) regarding the prevalence of opioid abuse in interventional pain medicine practice settings.

I would like to take this opportunity to commend the authors for undertaking a study involving the subject of abuse. It is not an easy subject to deal with. This singular issue makes the issue of treating chronic pain with opioids very controversial. This study is also important because there is a paucity of studies regarding prescription drug abuse especially in the pain literature.

It is intriguing to find out that $24 \%$ of the study population were abusers even though only one criteria of abuse was taken into consideration, namely intentional doctor shopping. The number may be much higher if other criteria like failed drug screen were to be applied to the same group of patients. It is also interesting to note that Fishbain et al (2) in their review of various studies involving abuse in chronic pain population found that the prevalence of abuse ranged from $3.2 \%$ to $18.9 \%$ and commented that there is little evidence to say that addictive behaviors are common within the chronic pain population, which contradicts the clinical experience of many interventional pain practices. I feel that in my practice the prevalence of abusers closely matches that of Manchikanti et al (1) in spite of adequate screening. This fact underscores a very important fact that the incidence of drug abuse in the pain practice is substantial and we pain physicians must take this issue very seriously.

Although there was no statistical difference regarding the prevalence of nonphysiologcal symptoms and symptom magnification between the abuse and nonabuse groups, I was impressed with the differences (17\% in the abuse group vs $9 \%$ in the nonabuse group for nonphysiologcal symptoms and $17 \%$ vs $11 \%$ for symptom magnification). Perhaps, if the study group was larger, probably there would have been a statistical difference.

It was intriguing to see that there was higher incidence of depression seen among abusers.

It would be interesting to find out if there is a difference between the groups in terms of benzodiazepine use, patients on welfare, patients on disability, patients in whom the etiology of pain cannot be determined, patients who are focused on opioids and in patients who have opioid overuse.

\author{
Sairam Atluri, MD \\ Eastern Cincinnati Pain Management Associates \\ 10160 Meadowknoll Drive \\ Loveland $\mathrm{OH} 45140$
}

\section{REFERENCES}

1. Manchikanti L, Pampati V, Damron K et al. Prevalence of opioid abuse in interventional pain medicine practice settings: A randomized clinical evaluation: Pain Physician 2001; 4:358-365.

2. Fishbain DA, Rosomoff HL, Rosomoff RS. Drug abuse, dependence, and addiction in chronic pain patients. Clin J Pain 1992; 8:77.

\section{In Response:}

We would like to thank Dr. Atluri for his kind comments on this article. We also appreciate his comments on the issue of non-physiological signs, symptoms, and symptom magnification, as he accurately points out that if the study population was larger, we would have been able to show statistically significant differences. We also agree that we further need to look into various issues such as benzodiazepine use, other controlled substance use, as well as multiple factors influencing drug abuse. We welcome evaluations on these subjects.

Laxmaiah Manchikanti, M.D.

Bert Fellows, MA

Pain Management Center of Paducah

2831 Lone Oak Road

Paducah KY 42003 